\title{
Implementasi SMS Gateway sebagai Media Penyebar Informasi Akademik di Kampus UPI Cibiru
}

\author{
Fahmi Candra Permana ${ }^{1}$, Feri Hidayatullah Firmansyah ${ }^{2}$, Intan Permata Sari ${ }^{3}$ \\ 1,2,3 Program Studi Pendidikan Multimedia, Kampus UPI di Cibiru, \\ Universitas Pendidikan Indonesia \\ ${ }^{1}$ fahmi.candrap@upi.edu, ${ }^{2}$ feri.firmansyah@upi.edu, ${ }^{3}$ intanpermatasari@upi.edu
}

\begin{abstract}
Abstrak
Keterlambatan dalam menerima informasi merupakan suatu hal yang dapat menghambat tujuan dari informasi tersebut, oleh karena itu dalam era digital saat ini penyebaran informasi yang cepat merupakan salah satu hal yang dibutuhkan agar informasi dapat segera dimanfaatkan dengan baik sebagaimana mestinya. Salah satu solusi dari permasalahan itu adalah dengan membuat media penyebar informasi secara cepat berbasis SMS Gateway. Dengan menggunakan SMS Gateway suatu sistem dapat menghubungkan satu orang dengan beberapa orang sekaligus tanpa batasan anggota penerima maupun koneksi internet dari semua pihak, berbeda dengan grup Whatsapp Messenger yang hanya bisa menampung maksimal 256 anggota dan harus selalu terkoneksi internet untuk mengaksesnya. Dalam penelitian ini dirancang sebuah aplikasi yang memanfaatkan teknologi berbasis SMS Gateway dengan menggunakan Gammu sebagai aplikasi utama SMS Gateway, framework PHP sebagai tampilan antarmuka, serta MySQL sebagai database penyimpanan. Penelitian telah menghasilkan suatu sistem berbasis SMS Gateway sebagai sarana penyebar informasi akademik di lingkungan Kampus UPI di Cibiru yang dapat digunakan untuk mengirim pesan keseluruh civitas akademika secara cepat.
\end{abstract}

Keywords: SMS, Gateway, Messengger, Gammu.Informasi.

\section{Pendahuluan}

Kemampuan seseorang dalam menerima dan menyampaikan informasi sangatlah pent-ing, termasuk kecepatan dalam menerima informasi tersebut agar informasi tersebut bisa dimanfaaatkan sebagaimana mestinya. Karena jika sampai terjadi keterlambatan dalam menerima informasi, hal itu bisa membuat manfaat dari informasi yang sampai itu menjadi berkurang atau malah menjadi tidak bermanfaat sama sekali karena dibutuhkan aksi dari informasi terse-but berbasis waktu yang terus berjalan.Menurut Direktur UPI Kampus Cibiru Dr. Asep Herry Hernawan, M.Pd. saat ini masalah media penyebaran informasi di kampus UPI Cibiru ini bisa sedikit ditanggulangi dengan menggunakan grup Whatsapp, tetapi solusi ini masih sedikit bermasalah. Karena grup Whatsapp hanya dapat menampung maksimal 256 anggota saja, se-dangkan seluruh civitas akademika di kampus UPI Cibiru jumlah lebih dari 500 orang. Selain itu tidak semua orang membaca seluruh isi pesan dalam grup Whatsapp, dan tidak semua orang paket data internetnya selalu aktif, yang membuat pesan tidak dapat langsung ter-sampaikan.

SMS atau Short Message Service merupakan salah satu komunikasi dengan teks melalui perangkat bergerak (mobile device). SMS merupakan salah satu media yang paling banyak digunakan sekarang ini, karena selain murah, prosesnya sangat cepat dan langsung pada tujuan [2]. Seiring dengan berkembangnya teknologi SMS tidak hanya digunakan antara satu pengguna dengan satu pengguna lainnya saja, tetapi saat ini suda ada teknologi SMS Gateway. Dengan adanya teknologi SMS Gateway, seorang admin dari aplikasi yang berbasis SMS Gateway bisa mengirimkan pesan singkat yang berisi informasi secara langsung ke beberapa orang tanpa batasan jumlah penerima. Pada mulanya pemanfaatan teknologi SMS Gateway banyak digunakan dalam sektor bisnis dan perbankan. Sebagai contoh saat ini hampir semua Bank Nasional maupun Swasta sudah menggunakan SMS Gateway untuk memberikan info-masi kepada nasabah. Sehingga nasabah mendapat informasi detail baik jumlah saldo 
atau penarikan uang. Dengan kecepatan informasi pada SMS Gateway, peneliti sangat tertarik un-tuk menerapkan teknologi SMS Gateway pada sektor pendidikan khususnya pada perguruan tinggi dengan tahap awal menerapkannya pada kampus UPI Cibiru dengan tujuan memper-cepat proses penyampaian informasi mulai dari informasi beasiswa untuk mahasiswa, jadwal ujian tengah semester, ujian akhir semester, jadwal perwalian, hingga remind tugas, undangan meeting, dan penyampaian disposisi mengharuskan real time dalam pelaksanaannya, sehingga seluruh civitas akademik yang ada di Kampus UPI Cibiru yang harus mendapatkan informasi dapat menerima informasi dari Kampus UPI Cibiru sebagaimana mestinya.

Pemilihan teknologi SMS Gateway pada penelitian ini dikarenakan sebelumnya sudah pernah dilakukan sebagai media penyebar informasi, berikut adalah beberapa penelitian yang sudah dilakukan terkait dengan implementasi SMS Gateway : P. Jumri yang membahas Sistem Monitoring Konsultasi Bimbingan Akademik Mahasiswa dengan Notifikasi Realtime Berbasis SMS Gateway pada tahun 2012, kemudian T Husain, yang membahas Aplikasi pengingat waktu adzan berbasis SMS Gateway pada tahun 2017. Oleh karena itu karena perkembangan SMS gateway yang semakin berkembang, penulis tertarik untuk merancang aplikasi sms gateway sebagai media penyebar informasi akademik.

\section{Metode Penelitian}

\subsection{Metode Pencangan Aplikasi}

Metodologi penelitian yang digunakan dalam penelitian ini berbasis Pengembangan Sistem Informasi menggunakan metodologi proses pengembangan sistem (classic systems development process) dengan nama FAST (Framework for the Application of System Thinking) metode ini dipilih karena metode FAST memiliki standardisasi pengembangan sistem yang baik serta proses yang stabil dan terencana [1]. Berikut tahapan-tahapan pengembangan yang terjadi pada metode FAST dapat dilihat pada Gambar 1.

Metode Pengembangan Sistem FAST memiliki tahapan - tahapan[1] :

a. Scope Definition

Yaitu mendefinisikan lingkup sistem dan masalah-masalah, kesempatan- kesempatan dan perintah-perintah diterima yang memicu sistem tersebut.

b. Problem Analysis

Pada tahap ini, dilakukan analisa lebih mendalam mengenai sistem yang sudah ada. Tujuan dari tahap ini adalah untuk mempelajari dan memahami business process dari sistem yang ada dan domain permasalahan yang ditemukan pada tahap penganalisaan awal (preliminary investigation). Dengan memahami business process dan problem domain dari sistem yang ada, maka dapat dihasilkan suatu system improvement objective yang mencangkup problems, opportunities, dan directives dari sistem yang ada, dan juga constraint dalam pengembangan sistem yang baru.

c. Requirement Analysis

- Mengidentifikasi dan menyatakan persyaratan sistem;

- Membuat prioritas persyaratan sistem;

- Memperbarui atau memperhalus rencana proyek;

- Mengkomunikasikan pernyataan persyaratan.

d. Logical Design

Pada tahapan ini dilakukan perancangan logika untuk menerjemahkan persyaratanpersyaratan bisnis ke model-model sistem. Perancangan logika berupa pemodelan data akan digambarkan menggunakan Entity Relationship Diagram (ERD) dan pemodelan proses digambarkan menggunakan Data Flow Diagrams (DFD).

e. Decision Analysis

Tahapan ini menganalisis solusi terbaik untuk kebutuhan sistem yang akan dikembangkan. Analisa keputusan bertujuan mengidentifikasi berbagai alternatif kandidat solusi untuk pengembangan sistem. Kandidat solusi sistem akan dibandingkan berdasarkan karakteristik proses bisnis yang terkomputerisasi, keuntungan, software dan 
hardware serta perangkat lunak yang digunakan pendukung sistem guna memilih kandidat terbaik yang akan digunakan dalam pengembangan sistem.

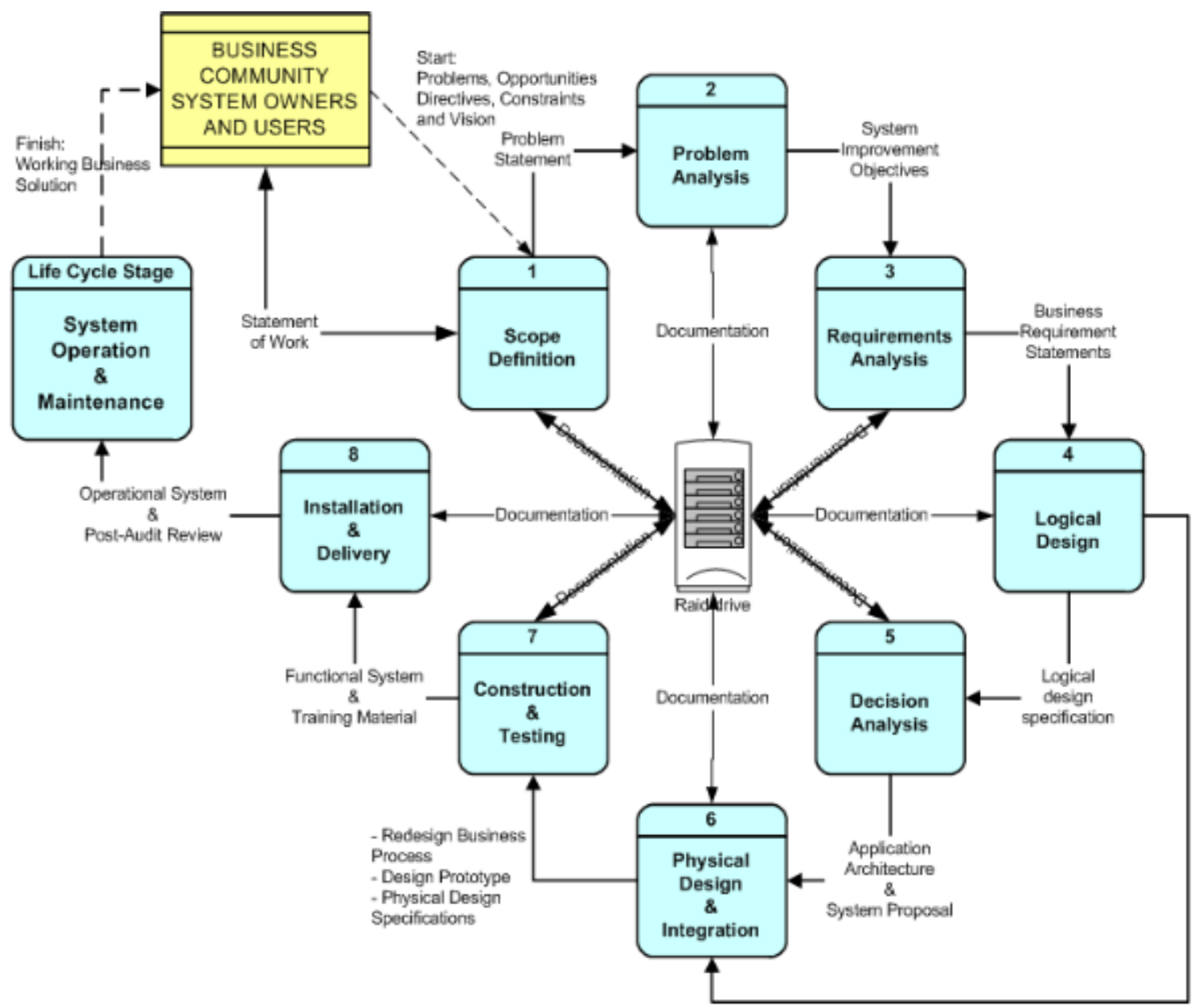

Gambar 1. Metode Pengembangan Sistem FAST [1].

\section{f. Physical Design and Integration}

Tahapan ini pernerjemahan persyaratan-persyaratan pengguna bisnis ke dalam model sistem yang mengilustrasikan implementasi teknis persyaratan-persyaratan pengguna sistem yang akan dikembangkan. Perancangan logika dengan tools DFD (Data Flow Diagram) yang telah dibuat sebelumnya ditransformasikan menjadi Physical Data Flow Diagram (PDFD). PDFD akan menggambarkan/memodelkan technical dan human design decisions dari implementasi sistem.

g. Construction and Testing

Tahapan ini membangun dan menguji sistem yang dikembangkan. Pembuatan dan penulisan program dilakukan setelah tahap desain selesai. Pada tahap ini juga dilakukan konversi dari hasil rancangan menjadi source code. Pada penelitian ini, bahasa pemograman yang akan digunakan adalah HTML (Hyper Text Markup Language) yang akan disatukan dengan PHP (Personal HyperText Preprocessor) dan MySQL sebagai database server. Setelah sistem sudah menjadi suatu perangkat lunak yang siap pakai, harus dilakukan pengujian dengan memfokuskan pada logika internal dari perangkat lunak, fungsi eksternal dan mencari segala kemungkinan masalah, serta memeriksa apakah perangkat lunak yang dikembangkan sudah sesuai dengan yang diharapkan sebelum perangkat lunak digunakan. Pengujian bertujuan memeriksa apakah perangkat lunak yang dihasilkan memiliki kesalahan atau tidak. Pada penelitian ini, Pengujian akan dilakukan dengan menggunakan black box testing, yaitu mengidentifikasi kesalahan yang 
berhubungan dengan kesalahan fungsionalitas yang tampak dalam kesalahan output, sehingga uji coba sistem lebih ditekankan pada bagaimana fungsi dari sistem yang dioperasikan berjalan.

h. Instalasi

Pada tahap ini akan dioperasikan sistem yang telah dibangun. Tahapan ini akan dimulai dengan men-deploy software hingga memberikan pelatihan kepada user mengenai penggunaan sistem yang telah dibangun.

\subsection{Proses Pengambilan Data}

Sebelum melakukan pengambilan data penerima informasi dalam sistem yang kami kembangkan, kami melakukan klasifikasi data terlebih dahulu, sehingga informasi yang disebarkan oleh sistem dapat bermanfaat sesuai kebutuhan dari penerima pesan tersebut. Dalam melakukan klasifikasi daftar penerima informasi dari sistem yang sedang kami kembangkan, kami mengklasifikasikannya menjadi seperti pada Tabel 1.

Tabel 1. Klasifikasi Penerima Pesan di Kampus UPI Cibiru

\begin{tabular}{l}
\hline \multicolumn{1}{c}{ Nama Kelompok } \\
\hline Dosen PGSD \\
\hline Dosen PGPAUD \\
\hline Dosen Pendidikan Multimedia \\
\hline Tendik UPI Cibiru \\
\hline Mahasiswa PGSD 2015 \\
\hline Mahasiswa PGSD 2016 \\
\hline Mahasiswa PGSD 2017 \\
\hline Mahasiswa PGSD 2018 \\
\hline Mahasiswa PGPAUD 2015 \\
\hline Mahasiswa PGPAUD 2016 \\
\hline Mahasiswa PGPAUD 2017 \\
\hline Mahasiswa Pendidikan Multimedia 2018 \\
\hline
\end{tabular}

Data yang kami kumpulkan dalam penelitian ini adalah nama dan nomor hp seluruh civitas akademika di lingkungan UPI Cibiru yang masih aktif, baik berstatus sebagai pegawai ataupun mahasiswa UPI di kampus Cibiru. Dalam aplikasi ini sendiri telah tersimpan sebanyak 1277 kontak dari seluruh Civitas akademika yang ada di lingkunan kampus UPI Cibiru. Data tersebut kami dapatkan dari Sistem Direktori Mahasiswa UPI (SIDIMAS UPI) sebagai sum-ber utama data mahasiswa UPI, namun karena setelah kami masuk kedalam sistem SIDIMAS UPI tersebut ada beberapa kendala yang kami temukan. Dalam SIDIMAS UPI masih banyak data yang tidak lengkap dan belum di perbaharui, oleh karena itu kami perlu melengkapi kekurangan tersebut dan melakukan validasi dari setiap kontak yang ada dalam SIDIMAS UPI. Proses validasi ini dilakukan secara langsung oleh mahasiswa yang ikut serta dalam melaksanakan penelitian ini, sehingga didapat data yang telah tervalidasi dan terklasifikasi sebagai berikut :

Tabel 2. Jumlah Data yang Terkumpul dan Terklasifikasikan

\begin{tabular}{lll}
\hline No & Nama Kelompok & Jumlah \\
\hline 1 & Dosen PGSD & 29 \\
\hline 2 & Dosen PGPAUD & 12 \\
\hline 3 & Dosen Pendidikan Multimedia & 6 \\
\hline
\end{tabular}




\begin{tabular}{lll}
\hline 4 & Tendik UPI Cibiru & 39 \\
\hline 5 & Mahasiswa PGSD 2015 & 115 \\
\hline 6 & Mahasiswa PGSD 2016 & 239 \\
\hline 7 & Mahasiswa PGSD 2017 & 233 \\
\hline 8 & Mahasiswa PGSD 2018 & 232 \\
\hline 9 & Mahasiswa PGPAUD 2015 & 57 \\
\hline 10 & Mahasiswa PGPAUD 2016 & 73 \\
\hline 11 & Mahasiswa PGPAUD 2017 & 77 \\
\hline 12 & Mahasiswa PGPAUD 2018 & 90 \\
\hline 13 & Mahasiswa Pendidikan Multimedia 2018 & 75 \\
\hline Jumlah Semua & 1277 \\
\hline
\end{tabular}

\section{Hasil dan Pembahasan}

Hasil dari penelitian ini adalah suatu aplikasi berbasis sms gateway yang dapat digunakan sebagai media penyebar informasi akademik utama dilingkungan Kampus UPI Cibiru. Dengan hasil penelitian diharapkan proses penyebaran informasi akademik di Kampus UPI Cibiru menjadi lebih cepat, efektif dan efisien, berikut hasil rancangan aplikasi yang sudah selesai dibangun dari penelitian ini:

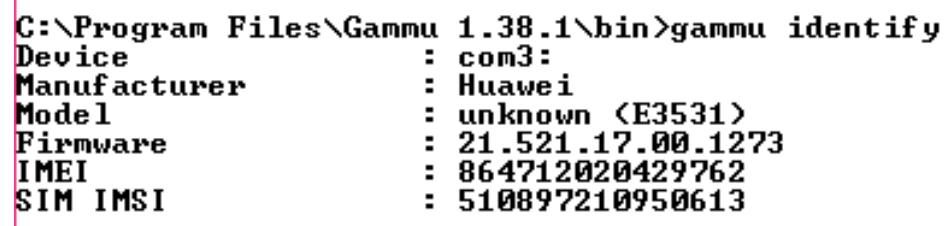

Gambar 2. Cek Status Port pada Modem yang Terinstall pada Komputer

Salah satu syarat aplikasi berbasis SMS Gateway dapat digunakan adalah diperlukan suatu hardware sebagai alat untuk mengirim pesan dari aplikasi, selain itu hardware yang terhubung pada komputer harus terhubung dan terinstall pada komputer, agar dapat terinstall diperlukan setting port dan pengecekan yang menunjukan aplikasi sudah terhubung dengan hardware yang dalam penelitian ini menggunakan modem yang terhubung pada komputer, pada Gambar 2 menunjukan bahwa aplikasi sudah terhubung dengan hardware pengirim SMS. Setelah modem terkoneksi aplikasi dapat langsung digunakan, berikut tampilan awal ketika aplikasi dibuka, dapat dilihat pada Gambar 3.

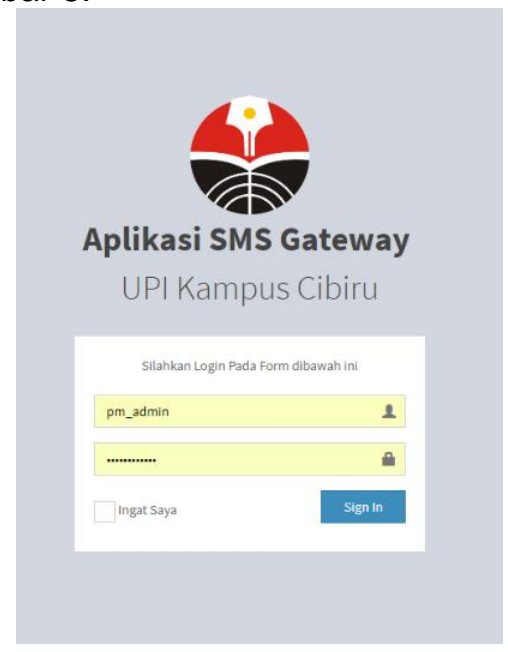

Gambar 3. Halaman Login Aplikasi 
Ketika pertama kali dibuka, halaman pertama yang dibuka adalah menu login aplikasi, adanya menu login pada aplikasi diperlukan agar hanya orang tertentu yang dapat menggunakan aplikasi ini, pada laman ini hanya seseorang yang mempunya user dan password dapat masuk / login pada aplikasi ini.
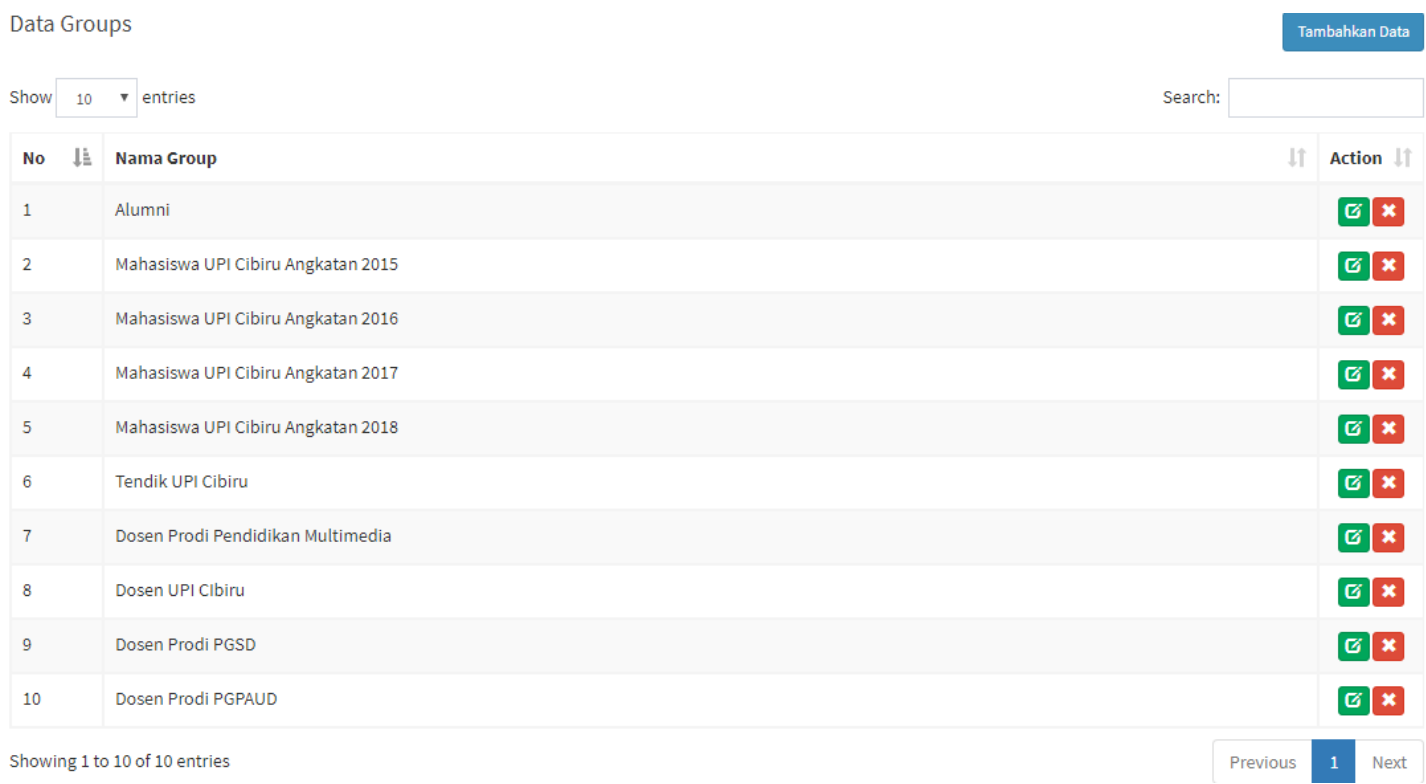

Gambar 4. Klasifikasi Grup Penerima di Lingkungan Kampus UPI Cibiru.

Agar informasi dapat disampaikan tepat sasaran maka harus dibentuk grup khusus sebagai metoda klasifikasi penerima informasi akademik di lingkungan kampus UPI Cibiru berdasarkan status penerima masing masing, daftar klasifikasi penerima informasi akademik di lingkungan Kampus UPI Cibiru dapat dilihat pada Gambar 4.

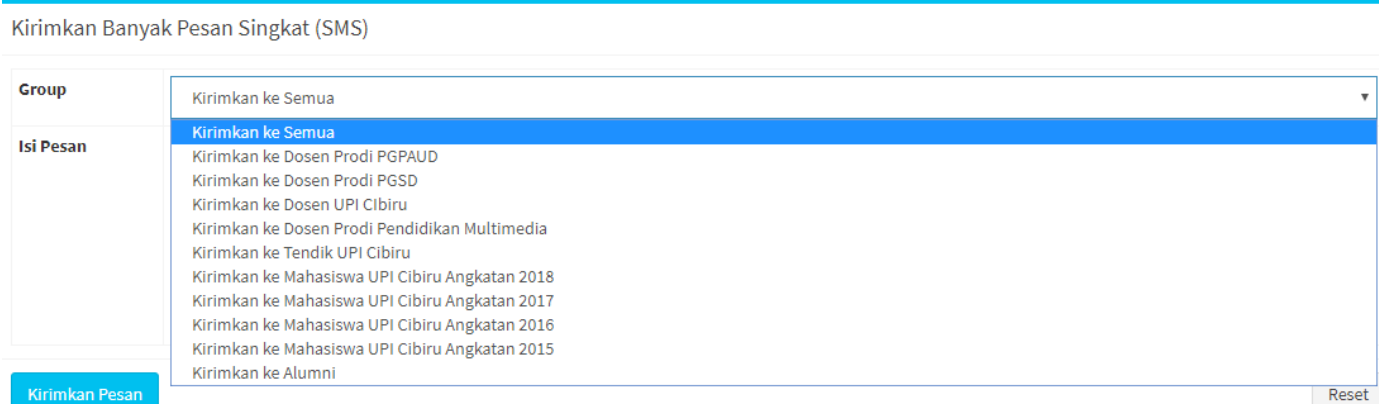

Gambar 5. Mengirim Pesan Sesuai dengan Klasifikasi Penerima.

Sebelum menuliskan pesan yang akan dikirim, seorang admin aplikasi diharuskan memilih daftar penerima pesan yagn akan dituliskan dan dikirim nantinya, dapat dilihat pada Gambar 5 .

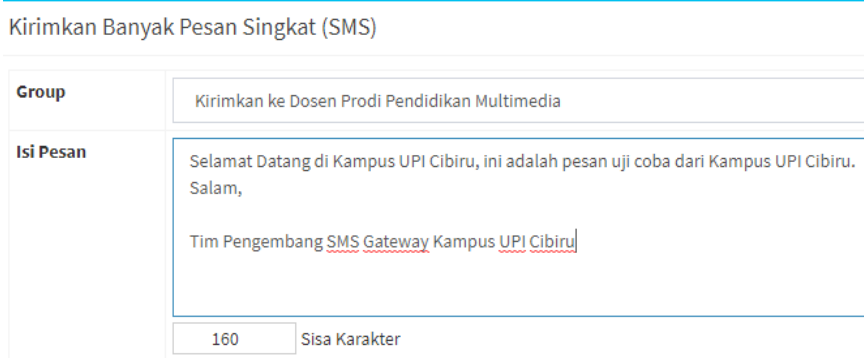


Gambar 6. Menulis Isi Pesan yang Akan Dikirim.

Setelah memilih daftar penerima pesan singkat, langkah selanjutnya adalah, menuliskan isi pesan yang akan dikirim, seperti pada Gambar 6 .



Gambar 7. Contoh Pesan yang Diterima Civitas Akdemika di Lingkungan Kampus UPI Cibiru.

Setelah pesan dikirim oleh admin aplikasi, Gambar 7. adalah pesan yang diterima oleh Civitas Akemika di Lingkungan Kampus UPI Cibiru.

Gambar 8. Daftar Penerima Informasi di Lingkungan Kampus UPI Cibiru.

Salah kelebihan dari teknologi SMS Gateway adalah tidak ada batasan jumlah penerima yang akan menerima pesan yang akan dikirim, Gambar 8. menunjukan daftar penerima informasi di lingkungan Kampus UPI Cibiru. 


\section{Kesimpulan}

Dengan menggunakan Bahasa Pemrograman HTML, PHP, beserta Bootstrap sebagai framework CSS untuk mempermudah mendesain/mengatur interface aplikasi, dengan MySQL sebagai DBMS untuk pengolahan admin aplikasi, klasifikasi penerima informasi, beserta daftar penerima informasi, kemudian Gammu sebagai service untuk mengirim SMS pada komputer, dapat dibangun suatu aplikasi berbasis SMS Gateway sebagai media penyebar informasi akademik di lingkungan Kampus UPI Cibiru yang dapat digunakan untuk mengirim pesan keseluruh civitas akademika secara cepat.

\section{References}

[1] Whitten, Jeffrey L. ; Dittman, Kevin C. ; Bentley, Lonnie D., Metode design dan analisa Sistem Bibliografi ed.6, Penerbit Andi. Yogyakarta: 2004

[2] T, Husain, "Perancangan Aplikasi Pengingat Waktu Adzan Berbasis Mikrokontroler dengan Trigger SMS Gateway Design Applications Reminder Time Adzan Based Microcontroller with Trigger SMS Gateway", Jurnal Voice of Informatics, 2017, pp 1-11

[3] R. Primartha, "SISTEM INFORMASI HASIL PERTANDINGAN PEKAN OLAH RAGA MAHASISWA ASEAN KE-17 BERBASIS SMS GATEWAY," in Konferensi Nasional Teknologi Informasi dan Aplikasi(KNTIA14), Palembang, 2014.

[4] P. M. Wikma, "SMS GATEWAY SMS Gateway adalah teknologi mengirim, menerima dan bahkan mengolah sms melalui komputer dan sistem komputerisasi (software)," 2014. [Online].

http://www.academia.edu/4080794/SMS_GATEWAY_SMS_Gateway_adalah_teknologi_ mengirim_menerima_dan_bahkan_mengolah_sms_melalui_komputer_dan_sistem_komp uterisasi_software. [Diakses April 2018].

[5] M. Afrina, "Pengembangan Model Sistem Informasi Perpustakaan Dengan Teknologi Informasi Berbasis Wireless Aplication Protocol (WAP) pada UNSRI," Jurusan Sistem Informasi, Fasilkom Unsri, pp. 1-9, 2012.

[6] J. . P. Jumri, "Perancangan Sistem Monitoring Konsultasi Bimbingan Akademik Mahasiswa dengan Notifikasi Realtime Berbasis SMS Gateway," Informatika, pp 3455, 2012.

[7] V. G. and A. P. , "Analisis Keputusan Pelanggan pada Sistem E-Tiket Maskapai Penerbangan Garuda Indonesia," in Konferensi Nasional Teknologi Informasi dan Aplikasi (KNTIA11), Palembang, 2011.

[8] Abdiansyah, "Membangun SMS-GATEWAY Untuk Pengisian Pulsa Elektronik Berbasis Web," Jurnal Sistem Informasi, vol. I, pp. 62-71, Agustus 2009.

[9] A. Kosasish, "Otomasi Perpustakaan Sekolah: Sebuah Pengenalan," Perpustakaan Universitas Negeri Malang (UM), pp. 1-13, 2009. 